Review article

\title{
Violence and its variants in nurses: A review article
}

\author{
Kaveh Jafari ${ }^{1}$, Mohammad Ali Heidari Gorji ${ }^{* *}$, Jabbar Heydari ${ }^{3}$, Yadollah Jannati ${ }^{4}$, Salma Ahmed
}

(Received: 7 Apr 2015; Accept: 20 Jul 2015)

\begin{abstract}
Background and Purpose: Violence is defined as unnecessary hostile behavior in clinical environments, which may lead to psychological abuse by colleagues. This systematic review aimed to evaluate violence and its associated factors among nurses.

Methods: In this study, we searched for articles and patented documentations published until December 2014 via databases such as PubMed, Medline, Scopus, Google Scholar, Iranian Journal Database (Magiran), Scientific Information Database (SID), IranMedex and Iranian Biomedical Journal. Using keywords such as violence, horizontal violence, lateral violence, prevalence, predisposing factors and bullying, we found 84 articles out of 19,000 search results.

Results: Violence has a variable definition in different cultures. Violent behavior in clinical environments is influenced by factors such as age, gender, work experience, work shifts, working hours and employment status of medical staff. In nurses, violence could lead to adverse outcomes, such as physical and psychological damages.

Conclusion: According to the results of this study, male and younger nurses are more frequently exposed to violent behavior compared to female and elder nurses. Therefore, nurses should be informed on the adverse effects of violent behavior. In this regard, authorities and management of medical centers should show zero tolerance for violent behaviors on behalf of nursing staff.
\end{abstract}

Keywords: Nurse, Outcome, Prevalence, Violence

\section{Introduction}

Human dignity is considered as a primary human right, which must be respected and protected (1). Violence is a major concern for professionals at different working environments (2). Concept of violence among medical professionals was first discussed by Susan Joe Roberts who described violent behavior as non-physical, intra-group and inter-group conflicts that underlie clinical situations (3). In this context, violent behavior is defined as direct mental annoyance inflicted by staff members at workplace (4). This intra-group behavior occurs due to a particular tendency, performance or behavior of nurses and causes major conflicts in the clinical environment $(1,5)$.

\section{Materials and methods}

This systemic review was conducted via searching in databases such as PubMed, Medline, ScienceDirect and Google Scholar using keywords such as violence, horizontal violence, lateral violence, violence definition, prevalence, predisposing factors, bullying, nursing and nurse.

Keywords were selected based on previous

\footnotetext{
${ }^{1}$ Mazandaran Heart Center, Mazandaran University of Medical Sciences, Sari, Iran

2,* Corresponding author: Department of Medical- Surgical Nursing, Faculty of Nursing and Midwifery, Mazandaran University of Medical Sciences, Sari, Iran. Email: heydarigorji@yahoo.com

${ }^{3}$ Department of Psychology, Faculty of Nursing and Midwifery, Mazandaran University of Medical Sciences, Sari, Iran

${ }^{4}$ Department of Psychiatric Nursing, Faculty of Nursing and Midwifery, Mazandaran University of Medical Sciences, Sari, Iran

${ }^{5}$ Faculty of Management Studies and Research, Department of Business Administration, Aligarh Muslim University, Aligarh, India
} 
studies, and Persian equivalents were used for searching in Iranian databases, including Iranian Journal Database (Magiran), Scientific Information Database (SID), Iranian Biomedical Journal and IranMedex. In addition, manual search was performed in order to confirm search results.

Considering the extensive research conducted on the issue of violence and violent behavior of medical staff, patients and their family, this study aimed to evaluate two concepts of horizontal violence and lateral violence among nurses and other medical staff. As such, articles focusing on violent behavior of patients and their family members were excluded from this study.

According to our findings, articles on the subject of violence have only been published in Persian and English. Initially, articles containing the desired keywords were selected without time limit, and eventually, qualitative and quantitative studies published until December 2014 were included in this review. Selected articles were mainly about violent behaviors among nurses and other medical staff, and studies focusing on horizontal violence were reviewed as well.

Case reports, medical conferences and abstracts were excluded from this study. In total, we found 1,084 articles, 643 of which were selected for primary evaluation. After eliminating irrelevant articles, 27 articles remained in the study. All articles were obtained in full text, and repetitive studies were excluded from the review.

\section{Results}

In total, we reviewed 27 articles, the majority of which were cross-sectional studies. In addition, one article was a comparative study, and one of the studies was performed in hospitals of Australia. Also, we included one case-control and one cohort study, and all selected articles were published during 2003-2014.

One of the reviewed studies was performed in east Azerbaijan province (Iran) using questionnaires designed by researchers. Another research was conducted in hospitals of Hong Kong, Japan. In the majority of studies about violence, data were collected using researcher-made and electronic questionnaires. In all these articles, more than $75 \%$ of nurses were reported to experience episodes of workplace violence.

Violence leads to physical and mental consequences. According to reports, single people are less exposed to abuse, and nurses with lower clinical experience are more frequently affected by violence. In addition, $90 \%$ of the reviewed articles indicated that male nurses were more commonly subjected to violent behavior.

According to the results of our review, violent behaviors are highly prevalent among nurses and medical staff; therefore, nursing managers and medical supervisors should be trained in order to eliminate these behaviors and change the attitude of medical staff towards other members of the professional community.

Regarding the high prevalence of violence and abuse among nurses and medical staff, it is recommended that comparative research be conducted as to distinguish between the methods used in different studies to evaluate the level of

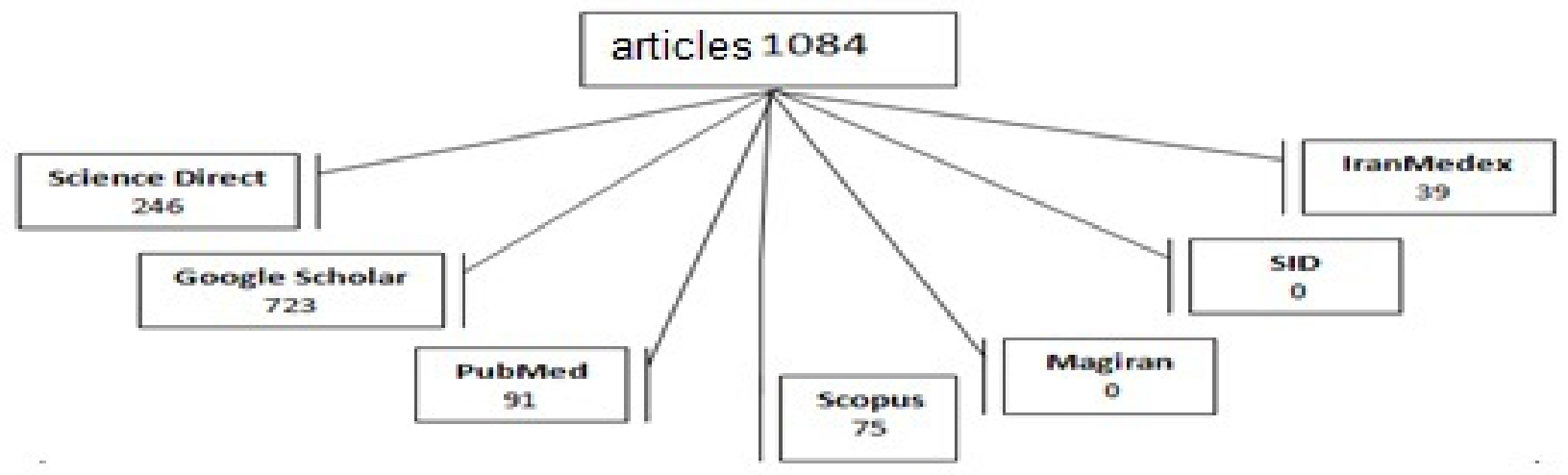

Diagram 1. Categorization of database which used in this review article 


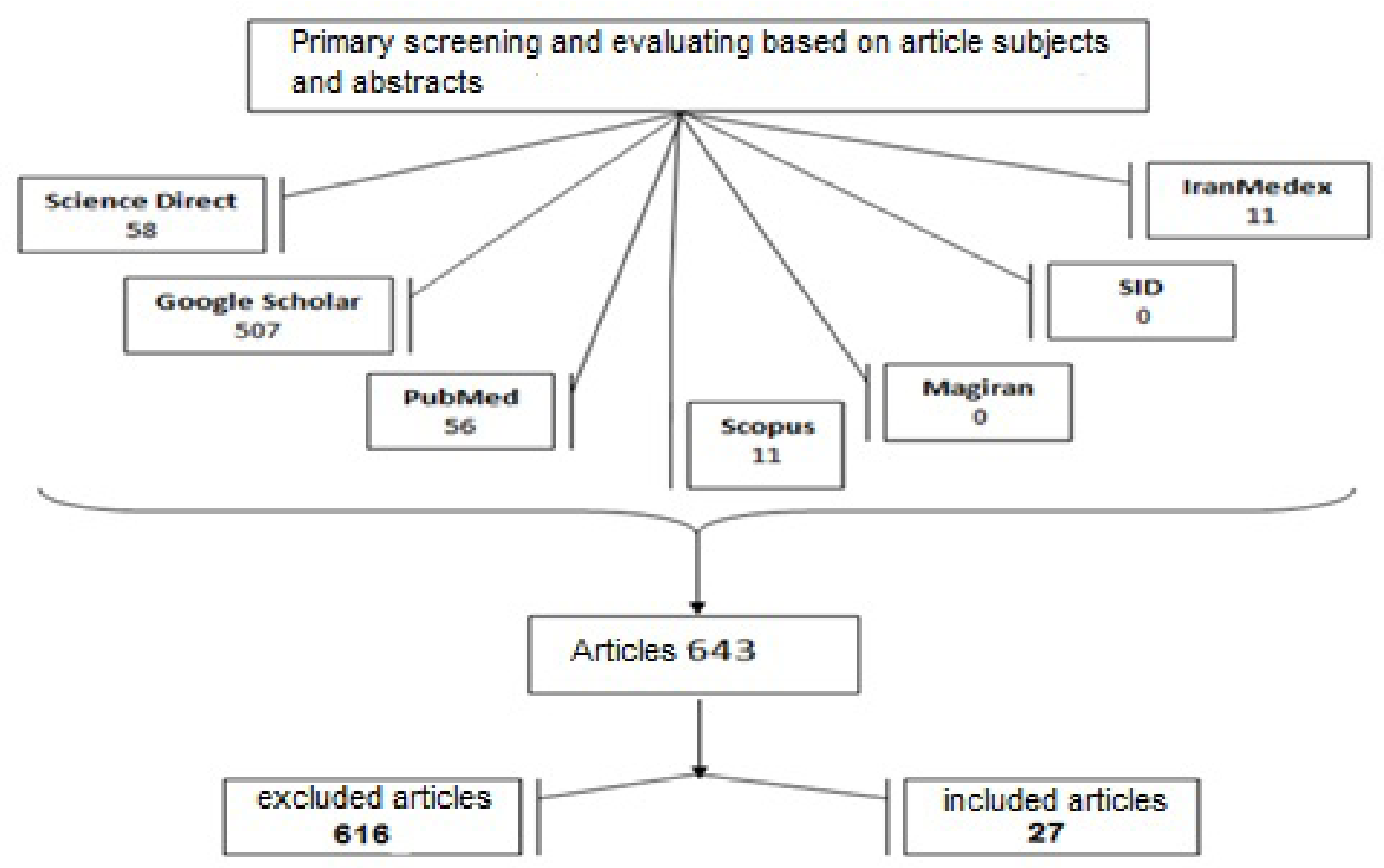

Diagram 2. Included and excluded articles

violence among nursing staff. According to the literature, nurses are the main cause of violence at workplace in the majority of cases.

\section{Discussion}

In the present study, we aimed to assess the frequency of abuse and horizontal violence, as well as their causes and consequences, among nurses.

According to several studies performed in different countries, horizontal violence among nurses occurs in case of physical, mental, verbal and non-verbal abuse (6). In general, violent behaviors towards nurses consist of verbal irony, obvious verbal insults, demolition of medical performance, salary cut and vandalism, physical assault and invasion of privacy (7-9).

In one study, Isfahani et al. (2014) evaluated the frequency of violence in hospitals of Azerbaijan province (Iran) in a sample size including male (17\%) and female (83\%) nursing staff with mean age of 32.8 years (10). In another study, Lee et al. (2006) assessed the level of violent behaviors among medical personnel in hospitals of Hong Kong (Japan) (male-to-female ratio: 34:3) (11). On the same note, Cheraqhi et al. (2012) conducted a survey in teaching hospitals of Hamadan (Iran) with the study population consisting of registered nurses (29.4\%), interns and nurses employed on short-term contracts (12).

According to the findings of Vessey et al. (2009), level of violence towards nursing staff at special wards and divisions was higher compared to nurses engaged at other departments (18\%) (13). In this regard, results obtained by Teymourzadeh et al. (2014) estimated the prevalence rate of abuse at $60 \%$ in major hospitals of Iran, which is correspondent with the results of the present study (14).

In another study, Young et al. (2014) reported that $94 \%$ of nurses experienced violent behavior and abuse within the past six months (15), while Kitaneh et al. (2012) stated that in public hospitals of 
Table 1. Summary of reviewed articles on prevalence of abuse and horizontal violence among nurses

\begin{tabular}{llll}
\hline Author/Year Study Objectives & Type of Study/Data Collection & $\begin{array}{l}\text { Study Population/ } \\
\text { Setting }\end{array}$ & Key Findings \\
\hline
\end{tabular}

Esfahani A.N To evaluate workplace

bullying among nurses in

(2014) Iran (2014)
162 nurses in four hospitals of west

Azerbaijan province/

Participants selected by

simple random sampling
Only $9 \%$ of nurses were frequently exposed to workplace violence/

$22 \%$ were occasionally bullied/

$69 \%$ were never exposed to bullying within the past year/

Verbal abuse

was the most common type of workplace violence ( $40 \%)$

\begin{tabular}{|c|c|c|c|}
\hline $\begin{array}{l}\text { RPW Kwok } \\
\text { et al. } \\
\text { (2006) }\end{array}$ & $\begin{array}{l}\text { To determine prevalence } \\
\text { and nature of workplace } \\
\text { violence towards nurses } \\
\text { and how nurses dealt with } \\
\text { aggression/Identify risk } \\
\text { factors associated with } \\
\text { violence in hospitals }\end{array}$ & $\begin{array}{l}\text { Cross-sectional study/ } \\
\text { Researcher-made questionnaires/ } \\
\text { Review of case reports using } \\
\text { researcher-made questionnaires }\end{array}$ & $\begin{array}{l}\text { All nursing staff, } \\
\text { except for those unable } \\
\text { to read Chinese or } \\
\text { without patient contact } \\
\text { (e.g., administrative } \\
\text { positions) completed } \\
\text { questionnaires at Queen } \\
\text { Mary Teaching Hospital } \\
\text { affiliated to Medical } \\
\text { University of Hong } \\
\text { Kong (Japan) }\end{array}$ \\
\hline $\begin{array}{l}\text { Cheraghi } \\
\text { M.A et al. } \\
\text { (2012) }\end{array}$ & $\begin{array}{l}\text { To assess viewpoint } \\
\text { of nurses at intensive } \\
\text { care units (ICUs) about } \\
\text { workplace violence }\end{array}$ & $\begin{array}{l}\text { Cross-sectional study/ } \\
\text { Modified Minnesota Workplace } \\
\text { Violence Questionnaire }\end{array}$ & $\begin{array}{l}\text { Quota sampling/ } \\
170 \text { nurses selected } \\
\text { from Therapeutic and } \\
\text { Educational Centers } \\
\text { (Hamadan, Iran; 2009) }\end{array}$ \\
\hline
\end{tabular}

420 nurses completed questionnaires (response rate: $25 \%$ )/320 nurses $(76 \%$; 95\% confidence interval [CI], 72-80\%) reported verbal abuse, (73\%), bullying (45\%), physical abuse $(18 \%)$ and sexual harassment $(12 \%) /$

Most nurses $(82 \%)$ with experience of verbal abuse confided in friends, family members or colleagues/ Some nurses $(42 \%)$ ignored abuse/Risk factors for workplace violence were working with male co-workers and employment at emergency department, community nursing service, department of orthopedics and trauma ward

Prevalence of violence was $74.1 \% /$ Most common types of violence were verbal abuse, threatening, physical battery and sexual assault/

Verbal abuse was most frequent/Limited legal pursuit since nurses believed it to be useless/Most nurses complained of violence from managers of institution

$70 \%$ of bullying cases reported by a predominant group of RNs $(\mathrm{n}=212) /$ Bullying occurred most frequently in medical-surgical ward $(23 \%)$, critical care unit $(18 \%)$, emergency ward $(12 \%)$, post anesthesia care unit $(9 \%)$ and obstetrics department $(7 \%)$ within a five-year period of employment at these wards (57\%)/ Perpetrators were senior nurses $(24 \%)$, charge nurses $(17 \%)$, nurse managers $(14 \%)$ and physicians $(8 \%)$ who publicly humiliated, isolated, excluded or excessively criticized RNs.

$\begin{array}{lll}\text { Vessey JA } & \text { and patterns of bullying } & \begin{array}{l}\text { so-item anonymous electronic } \\ \text { et al. }\end{array} \\ \text { (2009) } & \text { experienced among } & \begin{array}{l}\text { type, perpetrators and personal } \\ \text { and professional consequences } \\ \text { registered nurses (RNs) }\end{array} \\ & & \text { of bullying }\end{array}$

Quota sampling/ 303 RNs selected from across the U.S.

301 nurses completed questionnaires (response rate: 73\%)/

Cross-sectional study/ Standardized questionnaires designed in collaboration with the International Labor Office (ILO), International Health Organization (IHO), International Council of Nurses (ICN) and the Public Services International (PSI)

Teymourzadeh of nurses to workplace $\begin{array}{ll}\text { et al. } & \text { violence in a major }\end{array}$ (2014) teaching hospital in Tehran (2010)

\section{Descriptive study/}

Korean Work Environment

Scales/Workplace bullying

Yun $\mathrm{S}$ et al. perceived work

(2013)

environment and bullying

at workplace in Korean measured usi

of Negative Acts QuestionnaireRevised
All nurses employed at the teaching hospital affiliated to Tehran University of Medica Sciences (TUMS)

134 ICU nurses selected from five hospitals in Korea Over $70 \%$ of nurses were concerned about workplace violence Participants reported exposure to verbal abuse (64\%; CI: 59 $70 \%$ ), group bullying ( $29 \%$; CI: $24-34 \%$ ) and physical assault (12\%; CI: $9-16 \%)$ at least once within the past 12 months/Family members of patients were responsible for most of violence/ Nurses engaged at emergency department and outpatient clinics were more likely to report abuse/Nurses were unlikely to report violence to hospital managers, and $40 \%$ of nurses were unaware of existing policies on controlling abuse

$94.0 \%$ of ICU nurses experienced at least one negative act within the past six months/Prevalence of bullying was $17.2 \%$ according to operational bullying criteria/ ICU nurses reported work-related bullying more frequently than other types of abuse/ Significant negative correlations between nursing work environment and workplace bullying

Majority of respondents $(80.4 \%)$ reported exposure to violence within the past 12 months $/ 20.8 \%$ physical and $59.6 \%$ nonphysical abuse/ No statistical difference in violence exposure between physicians and nurses/Male nurses and physicians experienced more significant physical abuse compared to female professionals/ Logistic regression analysis indicated low female professionals/ Logistic regression analysis indicated low
work experience (odds ratio [OR]: $8.03,95 \%$ CI: 3.91-16.47) and low education level (OR: $3,95 \%$ CI: 1.29-6.67) as major risk factors for workplace violence/Assailants were mostly patient relatives and visitors, patients themselves and other colleagues/ Consequences of physical and non-physical abuse were significant/Only half of victims received treatment or compensation/Lack of reports for violence was a major concern and main causes were lack of appropriate policies, specific procedures and management support, previous experience of futile complaints and fear of consequences

$49 \%$ of nurses experienced abuse within the past 12 months $(82 \%$ verbal)/Female nurses at emergency department and geriatric psychiatry unit most commonly affected by violence/Statistically significant association between perception of fatigue, stress and job dissatisfaction with frequency of abuse $(\mathrm{P}<0.001) / 66 \%$ of job dissatisfaction with frequency of abuse $(\mathrm{P}<0.001) / 66 \%$ of
aggressors were frequently men $/ 53 \%$ of assaulted nurses did not ask for help after abuse

700 nurses $(37 \%$

Cross-sectional study/

Zampieron A health care centers/To

et al. verify an association

between characteristics

of aggressors and type

Anonymous multiple-choice

questionnaires personnel in 94 wards)

were selected from two

health care centers in northeast Italy

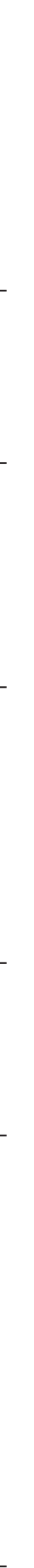


Continue Table 1.

\begin{tabular}{|c|c|c|c|c|}
\hline Author/Year & Study Objectives & Type of Study/Data Collection & $\begin{array}{l}\text { Study Population/ } \\
\text { Setting }\end{array}$ & Key Findings \\
\hline $\begin{array}{l}\text { Dumont et al. } \\
\text { (2012) }\end{array}$ & $\begin{array}{l}\text { To evaluate emotions } \\
\text { associated with HV } \\
\text { phenomenon }\end{array}$ & $\begin{array}{l}\text { Cross-sectional study/ } \\
\text { Dumont questionnaire }\end{array}$ & $\begin{array}{l}955 \text { participants selected } \\
\text { from } \\
\text { nursing staff of hospitals } \\
\text { in the U.S. }\end{array}$ & $\begin{array}{l}\text { No correlations found between nursing experience and frequency } \\
\text { of HV personal effects/Compared to female nurses, male nurses } \\
\text { experienced HV behaviors more frequently }(84 \%) / \text { Male nurses } \\
\text { experienced at least one personal effect of HV per month }(63 \%) / \\
\text { Statistically significant difference between young nurses }(21-30 \\
\text { years) in terms of reported violence (less frequent than older age } \\
\text { ranges [ } 41-50 \text { and } 51-60 \text { years]) }\end{array}$ \\
\hline $\begin{array}{l}\text { Algwaiz WM } \\
\text { et al. } \\
(2012)\end{array}$ & $\begin{array}{l}\text { To identify prevalence, } \\
\text { causes, types and } \\
\text { sources of workplace } \\
\text { abuse among health } \\
\text { professionals in public } \\
\text { hospitals of Saudi Arabia }\end{array}$ & $\begin{array}{l}\text { Cross-sectional study/ } \\
\text { Self-administered questionnaires }\end{array}$ & $\begin{array}{l}\text { Questionnaires } \\
\text { distributed randomly } \\
\text { among } 600 \text { physicians } \\
\text { and nurses/383 } \\
(63.8 \%) \text { completed } \\
\text { questionnaires at two } \\
\text { public hospitals in } \\
\text { Riyadh city (May-July } \\
\text { 2011) }\end{array}$ & $\begin{array}{l}\text { More than two-third }(67.4 \%) \text { of respondents were subjected } \\
\text { to violence within the past } 12 \text { months/Nurses more frequently } \\
\text { exposed to abuse compared to physicians }(\mathrm{P}<0.001) / \text { Male gender, } \\
\text { low experience and young age were associated with higher rate } \\
\text { of violence/Respondents reported excessive waiting time, staff } \\
\text { shortage and unmet demands of patients as the most common } \\
\text { causes of violence/Verbal abuse was the most common type of } \\
\text { workplace violence/Reasons for lack of abuse report were feeling } \\
\text { it to be unnecessary, previous experience of no prosecution and } \\
\text { fear of consequences }\end{array}$ \\
\hline $\begin{array}{l}\text { McKenna BG } \\
\text { et al. } \\
(2003)\end{array}$ & $\begin{array}{l}\text { To determine prevalence } \\
\text { of horizontal violence } \\
\text { experienced by nurses } \\
\text { during the first year of } \\
\text { practice }\end{array}$ & $\begin{array}{l}\text { Cross-sectional study/Self- } \\
\text { administered questionnaires }\end{array}$ & $\begin{array}{l}\text { Questionnaires were } \\
\text { anonymously mailed to } \\
\text { nurses registered before } \\
\text { November } 2000 \text { in New } \\
\text { Zealand }(\mathrm{n}=1,169) / 551 \\
\text { candidates completed } \\
\text { and returned } \\
\text { questionnaires }\end{array}$ & $\begin{array}{l}\text { Newly graduates of nursing experienced horizontal violence in all } \\
\text { clinical settings/Absenteeism, high number of respondents who } \\
\text { considered quitting nursing profession and scores of Impact of } \\
\text { Event Scale were indicative of significant effect of interpersonal } \\
\text { conflict/Nearly half of abuse events were not reported/Only } 12 \% \\
\text { of nurses who reported violence received formal debriefing/ } \\
\text { Majority of respondents had no training to manage abuse }\end{array}$ \\
\hline $\begin{array}{l}\text { Camerino D } \\
\text { et al. } \\
(2008)\end{array}$ & $\begin{array}{l}\text { To evaluate correlations } \\
\text { between responsible } \\
\text { individuals, health } \\
\text { care organization and } \\
\text { psychosocial factors with } \\
\text { frequency of different } \\
\text { types of workplace } \\
\text { violence }\end{array}$ & $\begin{array}{l}\text { Questionnaire-based, cross- } \\
\text { sectional, longitudinal design } \\
\text { used for two aspects of study }\end{array}$ & $\begin{array}{l}34,107 \text { nurses with } \\
\text { different qualifications/ } \\
\text { Response rate was } \\
55.1 \% \text { in cross-sectional } \\
\text { part and } 40.5 \% \text { in } \\
\text { follow-up phase/At } \\
\text { baseline, respondents } \\
\text { were mostly female } \\
(89.3 \%) \text {, within age } \\
\text { range of } 30-44 \text { years } \\
(52.9 \%) \text {, registered or } \\
\text { specialized (67.0\%), } \\
\text { mainly employed at } \\
\text { medico-surgical wards } \\
(36.3 \%) \text { and working } \\
\text { full-time (72.8\%) }\end{array}$ & $\begin{array}{l}\text { Higher level of adverse work-related factors was significantly } \\
\text { correlated with higher frequency of distinguished types of } \\
\text { abuse/ Significant correlations between psychosocial factors } \\
\text { and violence only in predicting organizational commitment } \\
\text { (even with very low effect size)/No correlations for perceived } \\
\text { health/Prevalence of distinguished types of abuse was variable } \\
\text { in different countries based on presence of adverse work-related } \\
\text { and nonwork-related factors }\end{array}$ \\
\hline
\end{tabular}

Palestine, $80.4 \%$ of nurses experienced workplace violence within the past 12 months (16). Similarly, results of a study performed by Spector (2014) in South Florida (U.S.) indicated that $67.2 \%$ of nurses experienced non-physical abuse, while $27.9 \%$ complained of oppression at workplace (17).

According to the findings of Zampieron et al. (2010), 86.6\% of nurses in Italian hospitals were subjected to abuse at workplace (18). Furthermore, Khalil et al. (2009) performed a study in public hospitals of Cape Town (South Africa) and reported that $51 \%$ of nurses experienced violence and abuse at different medical departments (19).

In the survey conducted by Vessey et al. (2009), $70 \%$ of nurses employed at hospitals of the United States had complaints of violent behavior and abuse (13). Moreover, they claimed that $78.5 \%$ of nurses with clinical experience of less than five years decided to change their job due to high rate of workplace violence, which is consistent with the results of the present study (13).

On the other hand, Cheraqhi et al. (2012) estimated the prevalence of violence at $52 \%$ and stated that $61.7 \%$ of nurses affected by violence refused to report the cases due to fear of possible consequences (12). By contrast, Vessey et al. (2009) claimed that $12 \%$ of nurses reported violence to nursing unions, while $65 \%$ adopted other approaches to report abuse (13). Correspondingly, results obtained by Celik et al. (2007) indicated that $70.5 \%$ of nurses reported workplace violence to higher authorities (9).

According to a study performed in hospitals of the United States in 2012, female nurses were more frequently subjected to violence compared to male nurses (20). However, Magnavita et al. (2012) observed that prevalence rate of workplace violence was higher among male nurses in hospitals of Italy (21). On the same note, Al-Gwaiz et al. 
(2012) reported that $73.7 \%$ of male nurses were subjected to violence in hospitals of Saudi Arabia (22). Furthermore, Kitaneh et al. (2012) claimed that although prevalence rate of abuse towards male nurses was higher compared to female nurses, there was no significant difference between male and female nurses regarding small episodes of violence (16).

According to the findings of Zampieron et al. (2010), $21 \%$ of violence at workplace came from nurses, $13 \%$ was caused by physicians, and $10 \%$ came from other medical staff. In total, $66 \%$ of violent behaviors were caused by male staff members, and female staff were mainly victims of abuse (18). Moreover, in a study evaluating the experience of nurses during their first years of employment, Mckenna et al. (2002) observed no correlation between gender of nurses and rate of violence (23). Similarly, results obtained by Farrell et al. (2006) were indicative of no significant difference between male and female nurses regarding the level of verbal abuse although male nurses were comparatively more affected by verbal abuse (32).

According to the following studies, female nurses are more commonly subjected to different types of violence compared to male nurses: 1) Camerino et al. (2008) (evaluation of the correlation between prevalence rate of violence and organizational, psychological and personal factors and their effects on health in eight European countries); 2) Ferrinho et al. (2003) (assessment of patterns of workplace violence in medical centers of Portugal); 3) Hegney et al. (2006) (evaluation of workplace violence in special wards of public and private hospitals and elderly care centers in Queensland in 2003); 4) James et al. (2000) (investigation of violence and abuse towards nurses in emergency departments of U.K); 5) Miedema et al. (2009) (evaluation of abuse and oppression among family members and co-workers of physicians and patients in hospitals of New Brunswick, and 6) Thomas et al. (2006) (retrospective study to determine common risk factors and problems associated with medical professions) (24-29).

According to the aforementioned studies, although female nurses are frequently targeted by abuse, male nurses tend to become victims of workplace violence due to interference in a wider range of issues (30). In another research conducted on the prevalence of horizontal violence at medical environments, no significant correlation was reported between age of medical staff and rate of violence; however, medical professionals over 40 years of age were found to experience higher levels of abuse.

In one study in Thailand, Dithisawatwet et al. (2014) claimed that violent behaviors were more prevalent towards nurses ageing 20-24 years compared to other age groups (31). Furthermore, findings of Al-Gwaiz et al. (2012) and Celik et al. (2007) suggested that the majority of violent behaviors came from people under 35 years of age $(9,22)$. In accordance with the aforementioned studies, Mckenna et al. (2012) reported that nurses under 30 years of age were more commonly subjected to workplace violence compared to other age groups (23). In this regard, results obtained by Farrell et al. (2006) in Australia indicated that nursing staff under 40 years of age are the main targets of abuse at work environments (32), while Perish and Anderson (2003) found no significant correlation between age of nurses and prevalence rate of workplace abuse (33).

In the study conducted by Perish and Anderson, no significant correlation was observed between work experience of nurses and rate of abuse (33). On the other hand, Vessey et al. (2009) reported that $24 \%$ of violence occurred for nurses with high experience levels. Moreover, their findings indicated that $58 \%$ of nurses with less than five years of clinical experience were affected by violence, and $26 \%$ of abuse occurred for nurses with 6-15 years of experience, while $16 \%$ of workplace violence affected nurses with 16 years of experience (13).

Similar to the present study, Al-Gwaiz et al. (2012) stated that nurses with less than 10 years of clinical experience were the main targets of violent behaviors at workplace (22). Furthermore, findings of Kitaneh et al. (2012) suggested that nurses with more than 10 years of experience were most frequently subjected to violence and abuse at workplace (16). On the other hand, Celik et al. (2007) observed that nurses with 10-14 years of experience were subjected to violent behavior of other colleagues (9). In their 
research, Dumont (2012) concluded that anxiety was the most significant contributing factor to workplace violence (20). Moreover, Kitaneh et al. (2012) reported the main consequences of violence to be anxiety (more than $50 \%$ ), as well as headache and fatigue (18.2\%), among nurses (16).

In another study, Lin and Lee $\mathrm{Yu}$ (2005) evaluated the effect of workplace violence on nurses in Southern Taiwan concluding that $62 \%$ of nurses were commonly subjected to verbal abuse. According to their findings, misunderstandings and personal issues were the most significant causes of abuse from physicians and other nurse colleagues. In addition, they suggested that single nurses experienced the highest level of abuse at work (34). Also, they found a negative correlation between age and work experience with violence among nurses, while workload was positively correlated with the level of abuse (35). In their research, Vessey et al. (2009) claimed that $17 \%$ of violence came from nursing shift supervisors, $14 \%$ was caused by nursing management, and $8 \%$ of abuse came from physicians (13).

In one study, Lindy and Schaefer (2010) investigated the effect of negative behaviors at workplace on the performance of nursing managements and concluded that all nurses employed at the management section experienced violence and abuse during their work shifts (36). On the other hand, results obtained by Hegney et al. (2010) indicated that $21.4 \%$ of violence towards nurses was caused by themselves, $10.9 \%$ was caused by physicians, $4.5 \%$ came from other medical staff, and $2.2 \%$ was caused by nursing management (37).

Findings of Celik et al. (2007) reported factors such as the ward of employment, age, years of experience, education status and marital status to have a significant effect on the occurrence of abuse and horizontal violence (9). Finally, Gerasi (2006) estimated the rate of violence at $39.49 \%$ in evening sifts, $14.65 \%$ in night shifts and $45.86 \%$ in morning shifts in a neurological ward (38).

\section{Conclusion}

According to the results of this review, prevalence rate of violence is relatively high among nurses engaged at different clinical departments. Workplace violence leads to decreased job security, job satisfaction, quality of patient care and patient safety.

Findings of this review indicated that male nurses are more frequently victims of abuse compared to female nurses, which could be due to the high tolerance of male nurses towards violent behaviors, as well as their behavior management. Furthermore, high level of abuse towards young nurses could be due to the fact that they seem inexperienced to other colleagues or patients.

Ineffective report systems and lack of appropriate punishment policies could lead to increased rate of workplace violence. Special training of medical staff through workshops of anger management could be effectual. Therefore, managers and policy makers in medical and health care services are expected to take proper measures in this regard.

One of the limitations of this study was that we were unable to access database contents completely, and as a result, some of the related articles that were not indexed in these databases could not be reviewed. In addition, we only searched for articles published in Persian and English. Nevertheless, findings of the current review could be beneficial for further investigation of workplace violence and abuse.

In conclusion, since rate of violence was comparatively higher in ICUs in different countries, it is recommended that future studies be conducted as to administrate effective strategies to eradicate the issue of workplace violence towards nurses.

\section{Conflict of interest}

The authors declare that they had no competing interests.

\section{Author's contributions}

K Jafari and MA Heidari Gorji have contributed to the designing, writing, revising and approving the final manuscript. J Heydari, Y Jannati and S Ahmed contributed in the process of providing the content of this issue. 


\section{Acknowledgements}

This study was extracted from a master's thesis conducted by Mr. Kaveh Jafari (MSc student of critical care nursing). Hereby, we extend our gratitude to the Deputy of Research at Mashhad University of Medical Sciences for the financial support of this research project.

\section{References}

1. Blanton BA. A horizontal violence position statement. London: Retrieved September; 1998.

2. Dargahi H, Gharib MI, Goodarzi M. Quality of work life in nursing employees of Tehran university of medical sciences hospitals. Hayat 2007; 13(2):13-21 (Peraian).

3. Taylor RA. Nurses' perceptions of horizontal violence. Boston: Northeastern University; 2013.

4. Bakker S. Covert violence in nursing: a Western Australian experience. [Phd Dissertation]. Australia: Edith Cowan University; 2012.

5. Work environment. Canadian Federation of Nurses Unions. Available from: www.nurseunions.ca/content.php?doc $=34$; 2007.

6. Bartholomew K. Ending nurse-to-nurse hostility: Why nurses eat their young and each other. Denvers, US: HC Pro, Inc; 2006.

7. Thomas SP. 'Horizontal Hostility': Nurses against themselves: how to resolve this threat to retention. Am J Nurs 2003; 103(10):87-8.

8. Griffin M. Teaching cognitive rehearsal as a shield for lateral violence: an intervention for newly licensed nurses. J Contin Educ Nurs 2004; 35(6):257-63.

9. Çelik SS, Celik Y, Ağırbaş İ, Uğurluoğlu Ö. Verbal and physical abuse against nurses in Turkey. Int Nurs Rev 2007; 54(4):359-66

10. Esfahani AN, Shahbazi G. Workplace bullying in nursing: The case of Azerbaijan province, Iran. Iran J Nurs Midwifery Res 2014; 19(4):409-15.

11. Kwok RP, Law YK, Li KE, Ng YC, Cheung MH, Fung VK, et al. Prevalence of workplace violence against nurses in Hong Kong. Hong Kong Med J 2006; 12(1):6-9.

12. Cheraghi MA, Noghan N, Moghimbeigi A, Bikmoradi A. Analysis of intensive care nurses "workplace violence". Critical Care 2012; 5(13):85-92.

13. Vessey JA, DeMarco RF, Gaffney DA, Budin WC. Bullying of staff registered nurses in the workplace: a preliminary study for developing personal and organizational strategies for the transformation of hostile to healthy workplace environments. J Prof Nurs 2009; 25(5):299-306.

14. Teymourzadeh E, Rashidian A, Arab M, Akbari-Sari A, Hakimzadeh SM. Nurses exposure to workplace violence in a large teaching hospital in Iran. Int J Health Policy Manag 2014; 3(6):301-5.

15. Yun S, Kang J, Lee YO, Yi Y. Work environment and workplace bullying among Korean intensive care unit nurses. Asian Nurs Res 2014; 8(3):219-25.

16. Kitaneh M, Hamdan M. Workplace violence against physicians and nurses in Palestinian public hospitals: a cross-sectional study. BMC Health Serv Res 2012; 12(1):469-78.

17. Spector PE, Zhou ZE, Che XX. Nurse exposure to physical and nonphysical violence, bullying, and sexual harassment: a quantitative review. Int J Nurs Stud 2014; 51(1):72-84.

18. Zampieron A, Galeazzo M, Turra S, Buja A. Perceived aggression towards nurses: study in two Italian health institutions. J Clin Nurs 2010; 19(15-16):2329-41.

19. Khalil D. Levels of violence among nurses in Cape Town public hospitals. Nurs Forum 2009; 44(3):207-17.

20. Dumont C, Meisinger S, Whitacre MJ, Corbin G. Nursing2012. Horizontal violence survey report. Nursing 2012; 42(1):44-9.

21. Magnavita N, Heponiemi T. Violence towards health care workers in a Public Health Care Facility in Italy: a repeated cross-sectional study. BMC Health Serv Res 2012; 12(1):108-17.

22. Algwaiz WM, Alghanim SA. Violence exposure among health care professionals in Saudi public hospitals. A preliminary investigation. Saudi Med J 2012; 33(1):76-82.

23. McKenna BG, Smith NA, Poole SJ, Coverdale JH. Horizontal violence: experiences of registered nurses in their first year of practice. J Adv Nurs 2003; 42(1):90-6.

24. Camerino D, Estryn-Behar M, Conway PM, van Der Heijden BI, Hasselhorn HM. Work-related factors and violence among nursing staff in the European NEXT study: a longitudinal cohort study. Int J Nurs Stud 2008; 45(1):35-50.

25. Ferrinho P, Biscaia A, Fronteira I, Craveiro I, Antunes AR, Conceição $C$, et al. Patterns of perceptions of workplace violence in the Portuguese health care sector. Hum Resour Health 2003; 1(1):11-22.

26. Hegney D, Eley R, Plank A, Buikstra E, Parker V. 
Workplace violence in Queensland, Australia: the results of a comparative study. Int J Nurs Pract 2006; 12(4):220-31.

27. James A, Madeley R, Dove A. Violence and aggression in the emergency department. Emerg Med J 2006; 23(6):431-4.

28. Miedema B, Easley J, Fortin P, Hamilton R, Tatemichi S. Disrespect, harassment, and abuse: all in a day's work for family physicians. Can Fam Physician 2009; 55(3):279-85.

29. Thomas NI, Brown ND, Hodges LC, Gandy J, Lawson L, Lord JE, et al. Risk profiles for four types of work-related injury among hospital employees: a case-control study. AAOHN J 2006; 54(2):61-8.

30. Gillespie GL, Gates DM, Miller M, Howard PK. Workplace violence in healthcare settings: risk factors and protective strategies. Rehabil Nurs 2010; 35(5):177-84.

31. Dithisawatwet S, Sawaengdee K, Tangcharoensathien V, Teerawit T, Thinkamrop B. Effect of workplace violence on the intention of leave a nursing career. J Sci Technol Hum 2014; 12(1):53-63.

32. Farrell GA, Bobrowski C, Bobrowski P. Scoping workplace aggression in nursing: findings from an Australian study. J Adv Nurs 2006; 55(6):778-87.

33. Anderson C, Parish M. Report of workplace violence by Hispanic nurses. J Transcult Nurs 2003; 14(3):237-43.

34. Lin YH, Liu HE. The impact of workplace violence on nurses in South Taiwan. Int J Nurs Stud 2005; 42(7):773-8.

35. Ekici D, Beder A. The effects of workplace bullying on physicians and nurses. Aust J Adv Nurs 2014; 31(4):24-33.

36. Lindy C, Schaefer F. Negative workplace behaviours: an ethical dilemma for nurse managers. J Nurs Manag 2010; 18(3):285-92.

37. Hegney D, Tuckett A, Parker D, Eley RM. Workplace violence: differences in perceptions of nursing work between those exposed and those not exposed: a crosssector analysis. Int J Nurs Pract 2010; 16(2):188-202.

38. Grassi L, Biancosino B, Marmai L, Kotrotsiou V, Zanchi P, Peron L, et al. Violence in psychiatric units: a 7-year Italian study of persistently assaultive patients. Soc Psychiatry Psychiatr Epidemiol 2006; 41(9):698-703. 